\title{
Implementation of parenting interventions through health services in
} Jamaica

Walker, Susan; Baker-Henningham, Helen; Chang, Susan; Powell, Christine; Lopez-Boo, Florencia; Grantham-McGregor, Sally

\section{Vulnerable Children and Youth Studies}

DOI:

$10.1080 / 17450128.2017 .1395100$

Published: 01/04/2018

Peer reviewed version

Cyswllt i'r cyhoeddiad / Link to publication

Dyfyniad o'r fersiwn a gyhoeddwyd / Citation for published version (APA):

Walker, S., Baker-Henningham, H., Chang, S., Powell, C., Lopez-Boo, F., \& GranthamMcGregor, S. (2018). Implementation of parenting interventions through health services in Jamaica. Vulnerable Children and Youth Studies, 13(2), 127-141.

https://doi.org/10.1080/17450128.2017.1395100

\footnotetext{
Hawliau Cyffredinol / General rights

Copyright and moral rights for the publications made accessible in the public portal are retained by the authors and/or other copyright owners and it is a condition of accessing publications that users recognise and abide by the legal requirements associated with these rights.

- Users may download and print one copy of any publication from the public portal for the purpose of private study or research.

- You may not further distribute the material or use it for any profit-making activity or commercial gain

- You may freely distribute the URL identifying the publication in the public portal ?
}

Take down policy

If you believe that this document breaches copyright please contact us providing details, and we will remove access to the work immediately and investigate your claim. 
Title: Implementation of parenting interventions through health services in Jamaica

Authors:

Walker SP, PhD, Professor ${ }^{1}$, corresponding author, ORCID 0000-0001-9494-1116

Baker-Henningham H, PhD, Reader ${ }^{1,2}$

Chang SM, PhD, Senior Lecturer ${ }^{1}$

Powell CA, PhD, Senior Lecturer ${ }^{1}$

Lopez-Boo F, PhD, Senior Economist ${ }^{3}$

Grantham-McGregor S, MD, Professor Emerita ${ }^{4}$

${ }^{1}$ Caribbean Institute for Health Research

The University of the West Indies,

Kingston 7, Jamaica

susan.walker@uwimona.edu.jm

susan.changlopez@uwimona.edu.jm

christine.powell@uwimona.edu.jm

${ }^{2}$ School of Psychology

Bangor University

Bangor, UK

h.henningham@bangor.ac.uk

${ }^{3}$ Inter-American Development Bank

Washington DC, USA

florencial@iadb.org

${ }^{4}$ Institute of Child Health

University College London

London, UK

sallymcgregor@yahoo.com

Word count: 4942

This work was supported by the Inter-American Development Bank. 
1 Title: Implementation of parenting interventions through health services in Jamaica

2

3

4

5

\begin{abstract}
Integration of parenting programmes that promote early child development with health services has been recommended as one strategy to reduce the large numbers of children not achieving their potential in low and middle income countries. There is limited information on implementation to guide integration for delivery at scale. We conducted a cluster randomized trial of 1) a home visit and 2) a health centre based intervention, in primary health services in Kingston, Jamaica, delivered separately or combined. The two approaches to delivery had similar effects on child cognition (home visit $0.34 \mathrm{SD}$; health centre 0.38 ). In this report, we describe the inputs required such as intervention content, staff training and supervision and resources. Intervention delivery was assessed through contacts achieved and quality documented. Views of health staff $(n=29)$ and mothers $(n=25)$ were obtained through qualitative interviews and analyzed using thematic content analysis. The interventions provided modeling of behaviours and activities, and interactive practice but varied in how this was conducted. Supervision was provided by the research team. Community health workers (CHWs) conducted $75 \%$ of planned home visits and $83 \%$ of mothers attended all 5 health centre sessions. CHWs were able to implement the interventions with adequate to good quality. Mothers and health staff perceived benefits for mothers' parenting practices and child development. Health staff also felt they personally benefited. Mothers who received both interventions preferred the home visit intervention and thought their child benefitted more. The main implementation challenges perceived by CHWs were engaging parents who were less interested, and conducting the intervention in addition to their existing workload. Staff workload was the main challenge reported by nurses. Sustainable implementation at scale would require investment in additional staff, particularly for programme management and supervision.
\end{abstract}

Key words: parenting, health services, implementation, child development 


\section{Introduction}

3 Millions of children in low and middle income countries do not attain their developmental

4 potential (Black et al, 2016) and interventions that assist parents to support children's early

5 development are needed (Berlinski \& Schady, 2015;Lake \& Chan, 2015). Integration of

6 parenting programmes with health and nutrition services has been recommended (Black \&

7 Dewey, 2014;Richter et al, 2016). Integrated models have included home visits (Powell et al,

8 2004), home visits combined with group sessions at health facilities (Hamadani et al,

9 2006; Yousafzai et al, 2014) and individual counseling or play at health clinics (Nahar et al,

10 2012;Potterton et al, 2010). There is therefore increasing impact evidence showing these

11 interventions are effective but much more limited information on implementation issues

12 (Yousafzai and Aboud, 2014). This information is needed to inform decisions around mode of

13 delivery, training and supervision required, and the barriers and enablers to intervention

14 implementation. Furthermore, investigating health workers' perceptions of a parenting

15 intervention is important if we plan to integrate it with their current workload as their views are

16 likely to affect compliance. Similarly mothers' perceptions may affect their engagement with the

17 intervention.

Interventions need to be effective in improving development and feasible as part of an existing

20 service and delivery at scale. A more intensive home visit intervention, delivered by community

21 health workers (CHWs) employed in health centres, benefited child development (Powell et al,

22 2004). CHWs are para-professionals given some training to support aspects of work within the

23 primary care system. Their role can vary from predominantly community visits to provide basic

24 services, to support for activities in centres. Education level, training and remuneration also vary 
1 by country (Haines et al, 2007). We adapted the previous home visit intervention to increase

2 feasibility of scale up by reducing visit frequency to fortnightly and visit duration to 30 minutes.

3 Duration of training for the $\mathrm{CHWs}$, and the amount of play materials provided to families were

4 reduced. We also developed a group intervention designed to be delivered at health centres

5 during routine child health clinics. This approach also benefited child cognitive development

6 (Chang et al, 2015). We conducted a cluster randomized trial of the two interventions in

7 Kingston, Jamaica. Twenty health centres were randomly assigned to the health centre

8 intervention or not and the home visit intervention or not, yielding four groups control, health

9 centre only, home visit only and both interventions. 396 mothers-infant pairs were recruited at

10 the six-week post-natal clinics (Walker et al, 2015). The primary impact outcome was children's

11 development and the interventions had similar effect sizes for development, health centre

12 compared with groups that did not receive this intervention $0.38 \mathrm{SD}$; home visit compared with

13 groups with no home visits $0.34 \mathrm{SD}$ (Walker et al, 2015). There was no suggestion that

14 combining the interventions had any additional benefits. The annual cost of the interventions,

15 including cost of health staff time for delivery, was US $\$ 100.9$ per child for the health centre

16 intervention and US\$ 245.1 per child for the home visiting intervention (Walker et al, 2015),

17 with the home visit intervention requiring more of the community health workers' time for visits

18 and travel to and from the homes.

19 In this paper, we report information needed for planning for implementation (Yousafzai \&

20 Aboud, 2014), including content, training and supervision of staff, and resources required. We

21 assessed effectiveness of intervention delivery through number of expected contacts achieved

22 and quality of the sessions. In a sub-sample of mothers and health staff we obtained information 
1 on perceived benefits and the views of the health staff on challenges that may have affected

2 implementation.

4 Methods

5 Sample

6 Information on intervention delivery (dosage, quality of sessions) was based on data available for

7 the full sample in all intervention centres. A sub-sample of participants were selected for the

8 qualitative interviews from the five clinics with the health centre intervention only and the five

9 conducting both the health centre and home visit interventions. Two CHWs and 1 nurse were

10 interviewed per clinic (1 nurse declined). Twenty-five mothers from the impact evaluation

11 participants were interviewed, 3 per clinic for the health centre intervention and 2 per clinic for

12 the combined intervention (fewer mothers were enrolled in centres delivering home visits).

13 CHWs were asked to suggest mothers who had varying levels of participation.

\section{Ethics}

15 Ethical approval was obtained from the University of the West Indies Ethics Committee and the

16 Advisory Panel on Ethics \& Medico-Legal Affairs and the South East Regional Health

17 Authority, Ministry of Health, Jamaica. The trial was registered with Current Controlled trials,

18 registration number ISRCTN43108304.

\section{Intervention design and resources}

20 In Jamaica, government primary health centres provide free child health clinics, staffed by nurses

21 and CHWs, for health checks and immunizations. Children attend clinics at 6 weeks, 3, 6, 9, 12

22 and 18 months of age. CHWs conduct growth measurements at child health clinics, have duties

23 at other clinics within the centre and conduct community visits to follow-up with clients. CHWs 
1 are full-time paid staff and typically have some secondary level education with a minimum of

2 complete primary level education. Most centres in the trial had 2 nurses (median 2, inter-quartile

3 range (IQR) 2,3) and 3 CHWs (IQR 2,3). Both interventions were delivered by CHWs and used

4 interactive strategies with demonstration of behaviors and activities, practice by parents and

5 encouragement and feedback, but differed in how the demonstration was provided, number of

6 sessions, and amount of practice and feedback. The interventions are described below with

7 further details in Table 1.

$8 \quad$ Health centre intervention

9 Attendance at child health clinics is high as immunizations provided are required for entry into

10 primary school. The intervention made use of time parents spend waiting to be seen by a nurse

11 and was delivered at the five health visits from 3-18 months. It would therefore reach most

12 families using the primary health services, and did not require additional time at the centre by the

13 parent.

14 Short films were shown of mothers doing behaviors we wished to encourage, followed by

15 interactive discussion, demonstration and practice of activities. Nine films of approximately 3

16 minutes each were developed with a team experienced in health education (Development Media

17 International, UK) and were filmed in Jamaica with five mother-child pairs. Three films were

18 shown at each visit. A different combination of topics was shown when the children in the

19 impact evaluation sample reached the age of the 3, 6, 9, 12 and 18 months health visits. DVDs

20 were produced with the set of 3 topics looped to be shown three times. Films were shown in the

21 clinic waiting area. Afterwards, the CHW led an interactive discussion of the films and

22 demonstrated the activities. Parents were encouraged to practice the activities and to continue

23 them at home. The CHWs also demonstrated how to make simple toys from household 
1 materials. The intervention was provided to all parents attending the clinic. The median number

2 of parents in the waiting areas was 37 (IQR 26,50).

3 At each visit, nurses gave the mothers message cards with simple language and pictures that

4 reinforced the topics on the films. They reviewed the cards with the mothers and encouraged

5 them to do the activities. The nurses gave parents a simple picture book when children were

6 aged 9 and 12 months, and at age 18 months a puzzle and 4 blocks.

7 Home visit intervention

8 The home visit intervention was based on the curriculum used previously in Jamaica (Grantham-

9 McGregor et al, 1991) modified to increase feasibility of scaling up. Visit frequency was reduced

10 from weekly to twice monthly, visit duration was shortened to 30 minutes, and fewer play

11 materials were provided. Children were visited from 6 to 18 months of age. CHWs conducted

12 play sessions with the mother and child to encourage mother-child interaction and show mothers

13 ways to promote development. CHWs were assigned up to 5 families, giving a maximum of 2-3

14 visits to be conducted weekly.

15 Training and supervision

16 Training workshops for CHWs for each intervention were conducted over three-days and

17 included review of content and methods, small group practice and role play (Table 1). CHWs

18 were given a manual with detailed guidelines on the intervention approach and activities. Nurses

19 were trained in the goals and content of the interventions and were asked to ensure that the clinic

20 sessions and home visits took place. Supervision of quality of implementation was provided by

21 the research team.

22 For the health centre intervention, a supervisor visited each centre prior to beginning the set of

23 topics for each of the 5 health visits, to review the topics and provide additional guidance in 
1 conducting discussions and practice. Quality of sessions was observed every 6 weeks in each

2 health centre. For home visits, quality of visits was observed monthly for each $\mathrm{CHW}$ and

3 supportive feedback given on the conduct of the visit. Further details on training and supervision

4 are given in Table 1.

5

6 Resources required to implement the interventions are summarized in Table 2. These included

7 staff time, materials provided to clinics and families and, in the case of the health centre

8 intervention, equipment to view the DVD. Resources for development of materials (films,

9 manuals) are not included. The home visit intervention was modified from an existing model

10 developed and evaluated over several years (Grantham-McGregor et al, 1991; Powell et al,

11 2004). The health centre intervention was newly designed, but informed by the earlier work.

12 Development included scripting of films and film production, development of training

13 workshops and manuals.

\section{Measurements}

\section{Intervention implementation}

17 Supervisors observed home visits $(n=180)$ and clinic sessions $(n=144)$ and rated the quality of

18 the CHW's interactions with the parents using checklists. The start and end time of the home

19 visit or discussion and demonstration session in the clinic were noted. In the health centres, four

20 aspects of CHW-parent interaction during discussion and demonstration session were rated using

21 a 3 point rating (hardly occurred, some of the time, most of the time). Supervisors rated whether

22 CHWs acknowledged and repeated parents' comments, moved around the group to involve

23 parents, and whether she praised parents for their contributions to the discussion or practice. The

24 final rating was of parent participation in the session. For the home visits, the supervisor rated as 
1 poor, adequate or good, the CHWs conduct of the steps to demonstrate the activities and her

2 relationship with the mother and child. The supervisor kept records of the number of home visits

3 conducted by each $\mathrm{CHW}$ and information on attendance at the clinic was obtained at the end of

4 the intervention by parent report. Information from the observation check lists were summarized

5 as median and IQR.

6 Qualitative interviews

7 At the end of the intervention, semi-structured interviews using an interview guide were

8 conducted by a researcher not involved in the interventions. Aims were to identify the benefits of

9 the program as perceived by health staff and mothers, challenges the health staff felt they faced

10 in implementation and whether participants had a preference between the two interventions.

11 Interviews were recorded then transcribed. CHWs and nurses were interviewed in a private area

12 in the health centre, and mothers in their homes. Interviews with mothers lasted approximately

1320 minutes, interviews with CHWs lasted between 30 minutes to 1 hour while interviews with

14 nurses lasted between 20-30 minutes.

16 Analysis

17 All interviews were taped and transcribed and the transcriptions were checked for accuracy

18 against the audiotape. The data were analysed using the framework approach (Ritchie \&

19 Spencer, 2002) in a five step process which involved: i) reading and rereading the transcripts, ii)

20 identifying themes and subthemes and constructing an index of codes grouped into categories,

21 iii) applying the codes to the individual transcripts, iv) rearranging the data in charts of each

22 theme and/or sub-theme with entries for each respondent under each theme and v) examining the 
1 charts to identify the key characteristics of the data. This process was conducted for each of the

2 three categories of respondents (mother, CHW and nurse) and in a final step the three analyses

3 were compared to look for commonalities and differences across type of respondent. The number

4 of participants who reported each theme/sub-theme was recorded to indicate the salience of each

5 within the data. Similar themes were evident across the respondents in the health centre only and

6 the combined health centre and home visit group and given the similarity in the themes and the

7 small numbers of respondents in the sample, we analysed the data from these two intervention

8 groups together.

9 The initial thematic framework and index of codes was developed by HBH and she trained a

10 research assistant to apply the codes to the transcripts and prepare the charts by theme and sub-

11 theme. The training involved coding five transcripts from each respondent-type together,

12 followed by coding a further three transcripts independently and comparing results. The research

13 assistant coded the remaining transcripts and counted the number of participants who reported

14 each theme or subtheme. Any on-going queries were discussed and resolved together. The final

15 stage of mapping and interpretation was conducted by HBH.

\section{Results}

Implementation

19 Eighty-three percent of mothers in the impact evaluation sample attended all 5 intervention

20 sessions. When mothers could not attend, children were usually brought to the clinic by their

21 father or other relatives. A median of 18 home visits (IQR 11-24) was conducted or 75\% of

22 targeted twice-monthly visits for one year from child age 6 to 18 months. Intended visit

23 duration was 30 minutes but actual median duration was 20 minutes. 
1 The sum of the four ratings of Parent-CHW interaction (potential total score 4-12) had a median

2 of 10 (IQR 9,11) indicating that the CHWs were generally able to conduct interactive sessions.

3 The home visit supervisor rated as poor, adequate or good, the CHWs conduct of the steps to

4 demonstrate the activities and her relationship with the mother and child. The CHWs had some

5 difficulty encouraging the mothers to talk about the activities ( $12.8 \%$ poor) and did not

6 encourage or praise the mothers sufficiently ( $40.4 \%$ poor). All other aspects of the visits had

7 combined adequate or good ratings of $90 \%$ or higher.

8

11 The themes and sub themes from the qualitative interviews are summarized in Table 3.

13 Benefits to Mothers and Children

14 Mothers, CHWs and nurses perceived similar benefits for mothers including increased

15 knowledge of child rearing and appropriate activities to do with young children, talking

16 and playing more with child and showing more love (examples are given in Table 4). Some

17 CHWs and nurses said the intervention increased mothers' motivation and a few thought it

18 led to more father involvement (Table 3).

19 Mothers and CHWs felt the interventions benefited children's development and prepared

20 them for school (Table 4). Mothers also mentioned children being exposed to new

21 experiences while CHWs felt there were benefits to children's self-esteem.

\section{Benefits to Health staff}

23 The CHWs reported that participating in the interventions increased their knowledge, job

24 satisfaction and interpersonal skills. For example: 
The interaction of the mothers... Yes they take part and some of them practice because when they come back you could see the babies enjoying what they doing. And so it makes me feel like I've been doing something. (Increased job satisfaction)

It help me to develop, mek me open up some more cause apparently, I use to be a shy person; so now I'm not a shy person (Better interpersonal skills)

Nurses also felt the intervention helped the CHWs' professional growth, as well as

increasing their own knowledge.

... I like what I see with the growth of my staff because you know just come to work every day ... you just do what you have to do but when you become integral in the growth and development of a child ... they can actually see this child improve (CHW, Professional growth)

Whenever they come at the different stages now, you're thinking okay what should they be doing, what should they be learning, what could they be learning and you are remembering the programme (Nurse, Increased knowledge)

\section{Challenges faced implementing the interventions}

The main challenges perceived by CHWs were difficulties with engaging some parents and staff

workload. CHWs enjoyed conducting the intervention with the majority of mothers, however felt some were uninterested or would complain. Mothers who were sometimes not at home during the pre-arranged time for the visits was also mentioned as a challenge.

Staff workload was perceived to affect both interventions. Related to this, some CHWs said that not all the CHWs were willing to conduct the discussions for the health centre intervention and so the work generally fell on one person.

Maybe I'm not on the road working this week but I need to do visits. There are times I need to go visit and I can't because we are short-staffed (home visit challenge)

I needed the other CHWs on the program to get in the discussions; I had to be giving the talks a lot, persons just back out (health centre challenge)

Staff workload was the main concern among nurses for example one said There are days when we really do feel overwhelmed, when the workload is heavy. 
2 Less consistently reported problems for the health centre included crowding and problems with

3 operating the television and DVD player. The challenges due to crowding and the overall level

4 of noise and distractions were greater in centres that had a general waiting area with no separate

5 area for the child health clinic.

If they come when we have a full clinic, sometime the ones that are supposed to be participating not getting the chance. The others, for instance, they come for family planning, they don't want to hear, they don't want to watch and it can be disruptive

\section{Preferences for type of intervention}

Of the ten mothers from centres with the combined intervention, nine indicated that they

preferred the home visits to the health centre intervention. The main reasons were that the home visit was more private, with less noise and distractions, and mothers felt their child benefited more as it was more personalized.

At the clinic sometimes too much noise... when you come up here, I kinda focus more on whey dem say you must do with her. Much better when dem come to my home.

Because by coming there, they get to spend more time with the child and know more about the child.

The mother who preferred the health centre intervention liked the videos and felt the CHW who visited her didn't spend enough time.

Six of 10 CHWs from centres providing both interventions also indicated a preference for home visits. Consistent with mothers, they said the home was less noisy, with more space and fewer distractions. They also felt mothers showed more interest and were easier to engage.

You spend more time with the mother and the child; a more quiet place so there is more interaction there.

The effectiveness is getting them at home, cause you get dem on a one on one 
2 Three CHWs felt that both interventions were important and did not express a preference. I wouldn't separate the two. One couldn't work without the other because you introduce it in the clinic and then there is the home visit to do follow-up.

6 Advantages they saw of the clinic included being able to work with a group of mothers and

7 mothers were available to participate whereas at home they were sometimes busy with household

8 chores. Advantages of the home visits included being able to see the home environment and

9 work with the mother one-on-one. One CHW who felt under pressure with the workload

10 preferred the health centre intervention, because she was concerned about the time needed for 11 home visiting.

\section{Discussion}

14 The results indicate that the interventions were implemented with adequate quality and were 15 valued by staff and parents who perceived benefits for themselves and the children. The findings 16 suggest the interventions have potential for delivery through health services. The health centre

17 intervention provides an alternative approach to delivering a parenting program. The choice of

18 intervention would depend on the context, for example culture, attendance rates at health centres

19 and infrastructure.

20 The interventions were designed to be feasible for CHWs to integrate with their usual duties.

21 The health centre intervention utilised time when the CHW was assigned to the child health 22 clinic, and required no additional visits to the centre by the mother. However, the setting posed

23 challenges with large group sizes, noise and overcrowding (Walker et al, 2015). In the

24 qualitative interviews, CHWs felt lack of interest of some parents was a challenge, and that some

25 CHWs were reluctant to lead the group sessions. Both mothers and CHWs felt that the clinic 
1 conditions made participation more difficult than in the home environment. Strategies to reduce

2 group size may be needed, including ensuring a separate waiting area in the centre for the child

3 health clinic.

4 For the home visit intervention, the number of families assigned per health worker was limited to

5 five. CHWs reported that it was still sometimes challenging to find time to conduct the visits and

6 overall a median of $75 \%$ of planned visits were made. Visits were shorter than intended,

7 however quality of the visits was adequate to good. For wider scale implementation additional

8 staff or targeting to families most in need would be necessary. A limitation of the study is that

9 due to resource constraints we were unable to conduct interviews with the mothers and CHWs

10 who participated in the home visit intervention only. We made the decision to omit this group

11 since similar interventions had been implemented previously.

12 The duration of training was the same for the two interventions and manuals were provided to

13 the CHWs. Frequency of supervision was similar and included observation and supportive

14 feedback. The reluctance of some CHWs to conduct the health centre discussions, and the

15 difficulties observed with some aspects of the home visits related to supporting mothers,

16 reinforce the need for continued supportive supervision for effective implementation. Strategies

17 for sustainable supervision are a critical issue for scale up of ECD parenting programmes

18 (Yousafzai \& Aboud, 2014).

19 Despite the difference in number of contacts, and individual versus group delivery, the

20 interventions had comparable benefits for child cognitive development. The use of films in the

21 health centre intervention to demonstrate behaviours, followed by practice may have allowed the

22 mothers to master the skills sufficiently to replicate them at home. Reinforcement by the nurses 
1 may also have helped mothers to see the behaviours introduced as important. It may be possible

2 to increase the benefits by including sessions at antenatal clinics and the first postnatal clinic at 6

3 weeks. Additional sessions beyond 18 months may be more difficult as routine clinic visits are

4 infrequent after this age.

5 Benefits from the home visit model are well established and replicated in other countries

6 (Grantham-McGregor \& Smith, 2016). The adaptations we made to facilitate scale up included

7 reduction in visit frequency, shorter visit duration and fewer play materials compared with earlier

8 evaluations. This modified approach yielded smaller and less comprehensive benefits than the

9 original model (Grantham-McGregor et al, 1991;Powell et al, 2004). The findings suggest that

10 some areas of the training need strengthening. Visit duration was shorter than intended so the

11 importance of taking time to engage with the mother and child and allow time for practice of

12 activities may need more emphasis. Additional time on building relationships with the families

13 may also be helpful to reinforce the CHWs understanding of a family's circumstances and why

14 they may not always be available for planned visits

15 CHWs had poor ratings for 2 aspects of the visit related to interaction with the mothers

16 suggesting that more time is needed to practice listening to, and interacting with the mother

17 across varying activities throughout the training and in encouraging and praising the mother.

18 These results are in line with a recent study of seven programs in Latin America and the

19 Caribbean showing that only a third of observed visitors provided positive reinforcement (praise)

20 to the caregivers and visitors had difficulty encouraging mothers to talk about activities in (Leer

21 et al, 2016). The duration of training was only 3 days compared with 10 to 30 days in earlier

22 trials. This may have been insufficient for this type of intervention which included more

23 activities with more detailed interaction than the health centre model. 
1 These findings also reinforce the need for supportive supervision and for adequate training of

2 supervisors so that they provide modeling and feedback when activities may be done too quickly

3 or not enough time is spent interacting with the mother and providing encouragement and praise.

4 The qualitative results indicated that the mothers valued the interventions and saw benefits for

5 themselves and their children. It is possible that despite asking health staff to suggest both

6 parents who had participated well and those who had not, that health staff nominated mainly

7 those who had participated well. This may tend to increase the number of mothers reporting

8 benefits. The health staff perceived similar benefits for mothers and children, and benefits for

9 themselves such as increased knowledge, job satisfaction and personal growth. The perceived

10 value to health staff is a positive finding for potential sustainability with appropriate support and

11 supervision.

12 The interventions ended at age 18 months and leave a gap in support at a critical period for

13 children's development until they are able to enter preschool. It is uncertain whether the benefits

14 seen will be sustainable and continuation of the home visit intervention, possibly targeted to high

15 risk families, may be necessary.

16 Nurses and CHWs expressed concerns about staff workload. The interventions were

17 implemented with existing health staff. Thus staff workload likely affected delivery, particularly

18 home visits where lack of staff may have prevented the CHWs from conducting visits. Part of

19 the rationale for integrating early childhood development (ECD) and health services is the

20 advantage of shared delivery. However, additional resources and staff are likely to be necessary

21 to expand services. In the Jamaican health service, CHWs are full-time paid staff. Challenges

22 with staff workload and ability to add duties may be greater where delivery agents are less 
1 formally part of the health service or volunteers, with competing responsibilities. No monetary

2 incentives were given to the CHWs and the only additional payment was compensation for

3 travelling expenses for home visits. Lack of incentives may be a greater issue where staff are

4 volunteers or only receive an honorarium.

5 The nurses' workload is likely to limit their ability to fully supervise ECD programmes.

6 Sustainability will require staff to manage the programme and to provide supervision

7 (monitoring and support). Calculation of intervention costs included supervision but not

8 management (Walker et al, 2015), benefit: cost ratios were high so additional costs should not

9 endanger the cost-effectiveness of the intervention.

10 Mothers who participated in both interventions, preferred the home visit to the health centre

11 intervention as they liked the privacy and thought their children benefited more. These

12 preferences may be influenced by culture and by the characteristics of the group session which

13 was part of routine clinics with large group sizes and limited opportunity for interaction among

14 mothers. Centre/group based interventions may be more attractive for mothers where they also

15 provide social interaction and support (Singla \& Kumbakumba, 2015).

16 CHWs also tended to prefer the home visit interventions although some did not indicate a

17 preference. Interactive group sessions are challenging to lead, particularly where conditions are

18 difficult as in noisy, crowded health clinics, and this needs to be considered when choosing

19 between a group model and individual interactions in the home. In a NGO implemented group

20 parenting intervention, delivery agents also perceived managing large groups to be a challenge

21 (Singla \& Kumbakumba, 2015). 
1 In conclusion, the interventions have potential for integration with health services, however, staff

2 workload and the need for supportive supervision will need to be addressed. While integration

3 with health services offers logistical benefits, effective ECD programmes will require sustainable

4 investment in additional staff, particularly for supervision, and for materials. The primary health

5 services in Jamaica and similar middle income countries are comparatively robust. In

6 developing integrated programmes consideration is also needed of the capacity of services and

7 infrastructure needed to enable effective implementation.

\section{Acknowledgements}

14 We thank Danielle Menzies-Toman for conducting the qualitative interviews, Janet DeSouza and 15 Michelle Williams for transcription and coding and the nurses, community health workers and 16 parents for their cooperation and making the study possible. We thank the Ministry of Health, 17 Jamaica, in particular, the Kingston and St Andrew Health Department, for facilitating the study 18 and their cooperation throughout. 


\section{References}

Berlinski,S. \& Schady,N. (2015) The Early Years. Child Well-Being and the Role of Public Policy, Palgrave Macmillan, New York.

Black,M.M. \& Dewey,K.G. (2014) Promoting equity through integrated early child development and nutrition interventions. Ann.N.Y.Acad.Sci., 1308, 1-10.

Black,M.M, Walker,S.P., Fernald,L.C.H., Andersen,C.T., DiGirolamo,A.M., Lu,C., McCoy,D.C., Fink,G., Shawar,Y.R., Shiffman,J., Devercelli,A.E., Wodon,Q.T., Vargas-

Baron,E., \& Grantham-McGregor,S.(2017) Early childhood development coming of age: science through the life course. Lancet 389, 77-90.

Chang,S.M., Grantham-McGregor,S.M., Powell,C.A., Vera-Hernandez,M., Lopez-Boo,F., Baker-Henningham,H., \& Walker,S.P. (2015) Integrating a Parenting Intervention With Routine Primary Health Care: A Cluster Randomized Trial. Pediatrics, 136, 272-280.

Grantham-McGregor,S.M., Powell,C.A., Walker,S.P., \& Himes,J.H. (1991) Nutritional supplementation, psychosocial stimulation, and mental development of stunted children: the Jamaican Study. Lancet, 338, 1-5.

Grantham-McGregor, S. \& Smith, J.A. (2016) Extending The Jamaican Early Childhood Development Intervention. Journal of Applied Research on Children: Informing Policy for Children at Risk 7: Issue 2, Article 4.

http://digitalcommons.library.tmc.edu/childrenatrisk/vol7/iss2/4

Haines,A., Sanders,D., Lehmann,U., Rowe,A.K., Lawn,J.E., Jan,S., Walker,D.G., \& Bhutta,Z. (2007) Achieving child survival goals: potential contribution of community health workers. Lancet, 369, 2121-2131.

Hamadani,J.D., Huda,S.N., Khatun,F., \& Grantham-McGregor,S.M. (2006) Psychosocial stimulation improves the development of undernourished children in rural Bangladesh. Journal of Nutrition, 136, 2645-2652.

Lake,A. \& Chan,M. (2015) Putting science into practice for early child development. Lancet, 385, $1816-1817$.

Leer,J., Lopez-Boo,F., Perez Exposito,A., \& Powell,C.A. Snapshot on the quality of seven home visit parenting programs in Latin America and the Caribbean. IDB-TN 1083. 2016. Washington DC, Inter-American Development Bank. IDB Technical Notes.

Nahar,B., Hossain,M.I., Hamadani,J.D., Ahmed,T., Huda,S.N., Grantham-McGregor,S.M., \& Persson,L.A. (2012) Effects of a community-based approach of food and psychosocial stimulation on growth and development of severely malnourished children in Bangladesh: a randomised trial. Eur.J Clin.Nutr., 66, 701-709. 
Potterton,J., Stewart,A., Cooper,P., \& Becker,P. (2010) The effect of a basic home stimulation programme on the development of young children infected with HIV. Developmental Medicine and Child Neurology, 52, 547-551.

Powell,C., Baker-Henningham,H., Walker,S., Gernay,J., \& Grantham-McGregor,S. (2004) Feasibility of integrating early stimulation into primary care for undernourished Jamaican children: cluster randomised controlled trial. $B M J, \mathbf{3 2 9}, 89-91$.

Richter,L.M., Daelmans,B., Lombardi,J., Heymann,J., Boo,F.L., Behrman,J.R., Lu,C., Lucas,J.E., Perez-Escamilla,R., Dua,T., Bhutta,Z.A., Stenberg,K., Gertler,P., \& Darmstadt,G.L. (2016) Investing in the foundation of sustainable development: pathways to scale up for early childhood development. Lancet 389, 103-118.

Ritchie,J. \& Spencer,L. (2002) Qualitative data analysis for applied policy research. The Qualitative Researcher's Companion (ed. by M. Huberman \& H. Miles), pp. 305-329. Sage Publications, London, UK.

Singla,D.R. \& Kumbakumba,E. (2015) The development and implementation of a theoryinformed, integrated mother-child intervention in rural Uganda. Soc.Sci.Med, 147, 242251.

Walker,S.P., Powell,C., Chang,S.M., Baker-Henningham,H., Grantham-McGregor,S., VeraHernandez,M., \& Lopez-Boo,F.(2015) Delivering parenting interventions through health services in the Caribbean: impact,acceptability and costs. Inter-American Development Bank. IDB Working Paper Serie, IDB-WP-642.

Yousafzai,A.K. \& Aboud,F. (2014) Review of implementation processes for integrated nutrition and psychosocial stimulation interventions. Ann.N.Y.Acad.Sci., 1308, 33-45.

Yousafzai,A.K., Rasheed,M.A., Rizvi,A., Armstrong,R., \& Bhutta,Z.A. (2014) Effect of integrated responsive stimulation and nutrition interventions in the Lady Health Worker programme in Pakistan on child development, growth, and health outcomes: a clusterrandomised factorial effectiveness trial. Lancet, 384, 1282-1293. 
Table 1. Content, delivery, training and supervision of home visit and health centre interventions

\begin{tabular}{|c|c|c|}
\hline & Home visits & Health centre groups \\
\hline Delivery & $\begin{array}{l}\text { CHW from health centre conducted play } \\
\text { session with mother and child to show } \\
\text { mother ways to promote her child's } \\
\text { development. }\end{array}$ & $\begin{array}{l}\text { Showing of films depicting mothers doing } \\
\text { behaviors to promote child development, } \\
\text { interactive discussion, demonstration and } \\
\text { practice of activities in waiting area. }\end{array}$ \\
\hline Contacts & $\begin{array}{l}\text { Target, fortnightly from age } 6-18 \\
\text { months. Median visits conducted } 18 \\
\text { (IQR } 11-24 \text { ) or } 75 \% \text { of target. }\end{array}$ & $\begin{array}{l}\text { At } 5 \text { routine immunization visits to health } \\
\text { centre }(3,6,9,12 \text { and } 18 \text { months). }\end{array}$ \\
\hline Content & $\begin{array}{l}\text { The visits followed a structured } \\
\text { curriculum including concepts such as } \\
\text { place, shape and size, and language } \\
\text { activities that encouraged mothers to } \\
\text { chat with their children and to label } \\
\text { objects and actions The CHWs } \\
\text { demonstrated new play and language } \\
\text { activities and supported the mother as } \\
\text { she practiced them with her child. } \\
\text { Mothers were encouraged to continue } \\
\text { play activities between the visits and to } \\
\text { integrate them in their daily routines. }\end{array}$ & $\begin{array}{l}9 \text { short films with the topics: Love, } \\
\text { Comforting baby, Talking to babies and } \\
\text { children, Praise, Using bath time to play and } \\
\text { learn, Looking at books, Simple toys mothers } \\
\text { can make, Drawing and games, and Puzzles. } \\
3 \text { topics covered at each health visit. After } \\
\text { showing the films CHWs led discussion of } \\
\text { topics, demonstrated activities shown (e.g. } \\
\text { playing peek-a-boo, looking at a book) and } \\
\text { encouraged the mothers to practice the } \\
\text { activity at the clinic and continue activities at } \\
\text { home. Message cards were given out by } \\
\text { nurses. }\end{array}$ \\
\hline Duration of sessions & $\begin{array}{l}\text { Planned visit length } 30 \text { minutes. Actual } \\
\text { median duration of visits (from visits } \\
\text { observed by supervisor) } 20 \text { minutes } \\
\text { (IQR 16-22). }\end{array}$ & $\begin{array}{l}\text { Films approximately } 20 \text { minutes, group } \\
\text { session median } 16 \text { minutes (IQR } 14-20 \text { min). }\end{array}$ \\
\hline Training & $\begin{array}{l}3 \text { day workshop for CHWs with } \\
\text { demonstration of toys, activities and } \\
\text { conduct of visits followed by small } \\
\text { group practice and role plays. Emphasis } \\
\text { was placed on the approach to the visit } \\
\text { including relationship with mother and } \\
\text { praise for mother and child. CHWs were } \\
\text { given a manual with overview of } \\
\text { program objectives and content, } \\
\text { guidelines to conducting visits and the } \\
\text { content to be covered in each of the } \\
\text { visits (toys, messages, activities). } \\
\text { One day workshop for nurses to review } \\
\text { program goals and content and nurse's } \\
\text { role in monitoring that visits were done. }\end{array}$ & $\begin{array}{l}\text { CHWs workshop over } 3 \text { days covering } \\
\text { review of films, training with role plays on } \\
\text { how to conduct interactive discussion of the } \\
\text { messages/activities on the films, and on } \\
\text { demonstrating activities. CHWs were given a } \\
\text { manual with overview of program objectives } \\
\text { and content, guidelines to engaging with } \\
\text { mothers in the discussion and demonstration } \\
\text { sessions, and the content for each of the } \\
\text { sessions, with suggested dialogue and details } \\
\text { of each activity. } \\
\text { Nurses workshop on } 2 \text { days for orientation to } \\
\text { program and CHW role, review of films, and } \\
\text { materials, nurse's role and review of message } \\
\text { cards. }\end{array}$ \\
\hline Supervision & $\begin{array}{l}\text { A supervisor accompanied the CHWs on } \\
\text { visits to monitor quality and provide } \\
\text { feedback ( } 1 \text { visit/CHW/month) The } \\
\text { supervisor also met with the CHWs at } \\
\text { the health centres once per month to } \\
\text { review visits and record books. }\end{array}$ & $\begin{array}{l}\text { Supervisor reviewed topics prior to delivery } \\
\text { of each new set of topics and provided } \\
\text { guidance in running the interactive } \\
\text { discussion, demonstration and practice. } \\
\text { Quality of implementation was monitored } \\
\text { approximately once every } 6 \text { weeks. }\end{array}$ \\
\hline
\end{tabular}


Table 2. Intervention resources and personnel time

\begin{tabular}{|c|c|c|}
\hline & Home visits & Health centre \\
\hline $\begin{array}{l}\text { Materials supplied to } \\
\text { clinic/clinic staff }\end{array}$ & $\begin{array}{l}\text { Manuals for CHWs, record books, bags } \\
\text { to carry materials for visits. }\end{array}$ & $\begin{array}{l}\text { TV, DVD players and installation costs (e.g. } \\
\text { grills, electrical work) DVDs. Manuals for } \\
\text { CHWs and nurse. Home-made } \\
\text { demonstration toys and materials to make } \\
\text { toys, container for toys. }\end{array}$ \\
\hline \multirow[t]{2}{*}{ Clinic staff time } & $\begin{array}{l}\text { CHW } 1.5 \text { hours per visit, including } \\
\text { travel time. } 15 \text { hours per month to visit } 5 \\
\text { children. }\end{array}$ & $\begin{array}{l}\text { CHW } 30 \text { minutes for preparation and } \\
\text { conduct of discussion session at child health } \\
\text { clinic. Total } 2 \text { hours month. }\end{array}$ \\
\hline & $\begin{array}{l}\text { Nurse } 30 \text { minutes/month to monitor that } \\
\text { CHW's made visits. }\end{array}$ & $\begin{array}{l}\text { Nurse } 2 \text { minutes/mother-child pair, to } \\
\text { review message card, encourage mother to } \\
\text { do activities. Total time variable depending } \\
\text { on number of children attending centre. }\end{array}$ \\
\hline $\begin{array}{l}\text { Play materials provided } \\
\text { to families }\end{array}$ & $\begin{array}{l}6 \text { Picture books, } 2 \text { puzzles. Toys made } \\
\text { from empty containers, soft toys (a ball } \\
\text { and doll) crayons, and wooden blocks. } \\
\text { Toys left in homes and exchanged at } \\
\text { next visit }\end{array}$ & $\begin{array}{l}2 \text { Picture Books, crayon, } 3 \text { piece puzzle, } 4 \\
\text { wooden blocks, } 6 \text { message cards, given to } \\
\text { each family }\end{array}$ \\
\hline Training resources & $\begin{array}{l}3 \text { day workshop for CHWs and } 1 \text { day } \\
\text { workshop for nurses, requiring trainer } \\
\text { time and costs for venue and } \\
\text { refreshments }\end{array}$ & $\begin{array}{l}3 \text { day workshop for CHWs and } 2 \text { day } \\
\text { workshop for nurses, requiring trainer time } \\
\text { and costs for venue and refreshments }\end{array}$ \\
\hline Supervisor time & $\begin{array}{l}\text { Supervisor to monitor visit quality and } \\
\text { provide feedback ( } 1 \text { visit/CHW/month) } \\
\text { and meet with CHWs at the health } \\
\text { centres once per month to review visits } \\
\text { and record books }\end{array}$ & $\begin{array}{l}\text { Supervisor to provide guidance in running } \\
\text { the discussion and practice and monitor } \\
\text { quality of implementation once every } 6 \\
\text { weeks }\end{array}$ \\
\hline
\end{tabular}


Table 3. Themes and sub-themes from qualitative interviews (values in parentheses are numbers reporting)

\begin{tabular}{|c|c|c|}
\hline Mothers $\mathrm{n}=25^{*}$ & CHWs n $=20 *$ & Nurses $n=9 *$ \\
\hline $\begin{array}{l}\text { Benefits to mothers } \\
\text { - Increased knowledge (20) } \\
\text { - Show more love (9) } \\
\text { - Play more with baby (7) } \\
\text { - Increased patience (6) } \\
\text { - Talk more to baby (5) } \\
\text { - Help bond with baby (3) } \\
\text { - Not helpful (1) } \\
\text { Benefits to child } \\
\text { - Child is smarter (12) } \\
\text { - Child exposed to new } \\
\text { - } \text { experiences (6) } \\
\text { - } \text { Child will be ready for school } \\
\text { - Child talks more (5) } \\
\text { Preference for home visit or clinic } \\
\text { intervention (total n=10) } \\
\text { - Prefer home visit (9) } \\
\text { - Prefer health centre (1) }\end{array}$ & 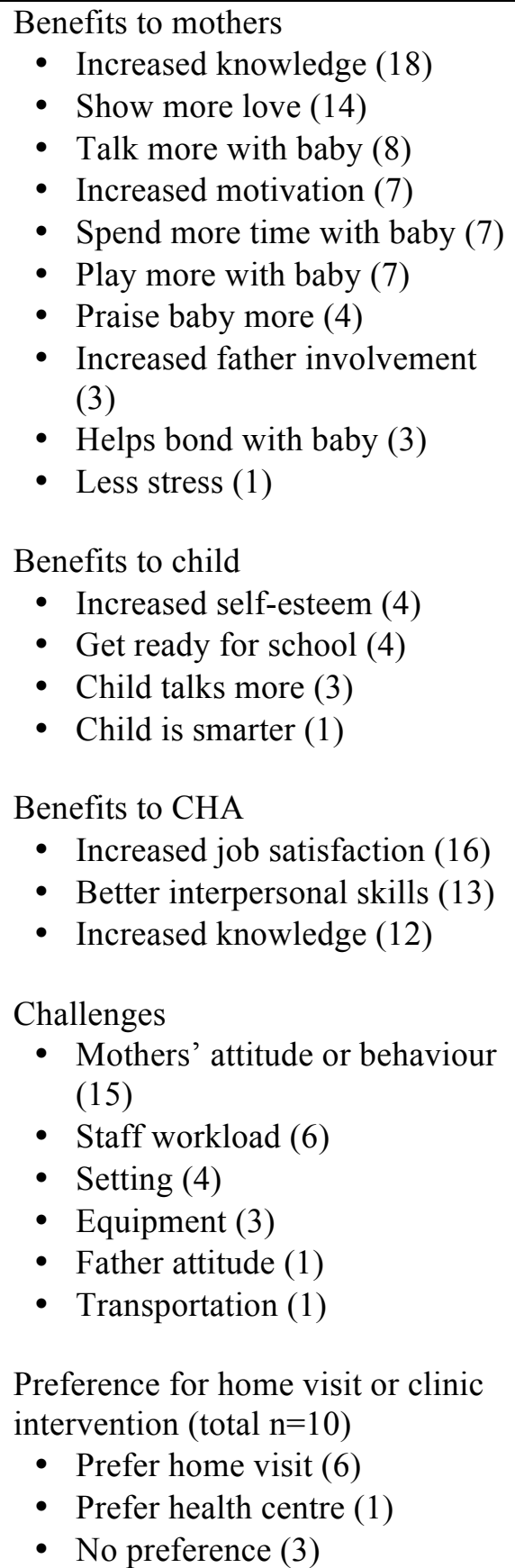 & $\begin{array}{l}\text { Benefits to mothers } \\
\text { - Increased knowledge (7) } \\
\text { - Show more love/ Bond with } \\
\text { - } \text { baby (5) } \\
\text { - } \text { Spcreased talk with baby (2) } \\
\text { - In } \\
\text { - } \text { Motivate time with baby } \\
\text { - More play (1) } \\
\text { Benefits to CHAs } \\
\text { - Professional growth (3) } \\
\text { Benefits to nurses } \\
\text { - Increased knowledge (3) } \\
\text { - Increased job satisfaction } \\
\text { - }(3) \\
\text { Chterpersonal skills (1) } \\
\text { - Staff workload (5) } \\
\text { - Equipment (2) } \\
\text { - Mothers' attitude (2) }\end{array}$ \\
\hline
\end{tabular}

*Mothers 15 from the clinic only intervention and 10 from the combined intervention;

* CHWs 10 from clinic only and 10 from combined intervention;

*Nurses 5 from clinic only and 4 from combined intervention. 
Table 4. Examples of perceived benefits of the intervention for mothers and children

\begin{tabular}{|c|c|}
\hline Theme & Quotations \\
\hline Benefits to mothers & $\begin{array}{l}\text { Mothers: } \\
\text { "I didn't know at that age you could show her a puzzle and she would get it. I wasn't thinking } \\
\text { of giving baby a puzzle" (increased knowledge) } \\
\text { "Yeah, cause when I have him I thought this is just a baby - you put pampers on him, make } \\
\text { sure that he eats and that's it. It just never occur to me that you must play with him." } \\
\text { (Increased knowledge) } \\
\text { "If she's crying, I don't feel that I'm spoiling her, I just take her up and hush her and love } \\
\text { her" (showing love) } \\
\text { "I didn't use to play with her before. I would just give her the toys and she would sit down } \\
\text { and play with them. Since the programme I'll sit with her, sing with her and play with her" } \\
\text { (Increased play with child) } \\
\text { For example, I take him for a walk and show him different, different things and talk about } \\
\text { them." (Increased talk) } \\
\text { CHWs: } \\
\text { Because some of them don't talk to their child. When the programme just started and you } \\
\text { asked them to talk to their babies it was a hard task for them but introducing it every day to } \\
\text { them, you see them start." (Talk more with baby) } \\
\text { "Like sometimes you will sit and you watch them and see how they love up the baby, kiss } \\
\text { them, play with them and so" (Show more love) } \\
\text { "Some of them didn't know what to do, especially some of the younger ones so when we } \\
\text { come out and show the videos and demonstrate, they demonstrate back to us and they learn" } \\
\text { (Increased knowledge) } \\
\text { "Some of them don't spend no time with their babies and like how this programme come in } \\
\text { now, they find time for the babies (Spend more time with baby) } \\
\text { Nurses: } \\
\text { "They saw they had a role not only to feed, to keep clean and other things, so the mental } \\
\text { ability of the child, they saw what they had to do" (Increased knowledge) } \\
\text { "The mothers' attitude towards the children, most of them, you know changed. Some of them } \\
\text { used to rough them and shout at them but they have learnt to take care of them and how to } \\
\text { love them" (Show more love) } \\
\text { I would notice that the mother keeps talking to the baby and they want nurse to know that } \\
\text { baby knows this and baby knows that so they say 'show nurse your nose' or 'show nurse your } \\
\text { eyes'. It's really good to see them doing that. (Increased talk with baby) }\end{array}$ \\
\hline Benefits to children & $\begin{array}{l}\text { Mothers: } \\
\text { "When they go to school now, they know these things already, so she will move faster" (Child } \\
\text { will be ready for school) } \\
\text { "With her skills, I think she is a bit advanced for her age. So I think it helped her in that way. } \\
\text { Let her be more advanced" (Child is smarter) } \\
\text { "It helps fill out his vocabulary" (Child talks more) } \\
\text { "It show her different things and everyday she does something new and learns something } \\
\text { new" (Child exposed to new experiences) } \\
\text { CHWs: } \\
\text { They clap themselves and praise themselves that would build their self-esteem" (Increased } \\
\text { self-esteem) } \\
\text { "When they reach school age they are far advanced than those in the classroom already - you } \\
\text { know - they know the book, the puzzle whatever" (Child will be ready for school) } \\
\text { "You have some children, they talking now. Because the parents talk to them, some of them } \\
\text { talk" (Child talks more) }\end{array}$ \\
\hline
\end{tabular}


